\title{
Etnografia Crítica de Sala de Aula: o Professor Pesquisador e o Pesquisador Professor em Colaboração*
}

\author{
Carmen Lúcia Guimarães de Mattos \\ Universidade Federal Fluminense (UFF)
}

Trata do relato de experiências sobre colaboração em pesquisa entre professores colaboradores e pesquisadores. Utiliza dados da pesquisa etnográfica intitulada: "Fracasso Escolar: imagens de explicações populares sobre 'dificuldades educacionais 'entre jovens de áreas rural e urbana no Estado do Rio de Janeiro ". Descreve que a prática colaborativa é essencial para a facilitação e a transformação das relações de interação em sala de aula, quando consideramos que o professor colaborador é um agente da pesquisa. Vê a inter-relação entre pesquisa e ensino como parte fundamental do processo de construção de conhecimento em sala de aula e a colaboração como uma prática que possibilita a genuína ajuda mútua e o intercâmbio entre o trabalho de pesquisa e ensino. Analisa as condições de desenvolvimento desse tipo de pesquisa em escolas públicas e suas limitações. Entende que tanto a etnografia crítica de sala de aula quanto a colaboração entre professor e pesquisador, na pesquisa educacional, constituem elementos para um avanço desta última no Brasil.

\section{Introdução}

A procura de colaboração bem-sucedida é uma constante no cotidiano de qualquer indivíduo, seja na família, no trabalho, numa

\footnotetext{
* Trabalho vinculado ao projeto de pesquisa "Imagens de explicações populares sobre 'dificuldades educacionais' entre jovens de áreas rural e urbana no Estado do Rio de Janeiro", que teve o apoio financeiro do Inep, da PROPP/UFF e do CNPq.
} 
situação de sala de aula ou qualquer outra atividade que envolva o relacionamento humano. Discutir os significados da colaboração na pesquisa é discutir a natureza do próprio processo de colaboração como também conviver com os dilemas que envolvem esse processo, especialmente quando se pesquisam as relações escolares que se situam no contexto da sala de aula - dilemas clássicos como, por exemplo, os inerentes ao processo de ensinar e aprender ou de pesquisar e ser pesquisado; dilemas mais comuns como o conflito de interesses entre professores, alunos e pesquisadores, bem como a dificuldade no planejamento antecipado das questões a serem investigadas, que aparecem, geralmente, associadas a temas igualmente familiares como: diálogo, confiança e risco, compondo o quadro das categorias fundamentais para a análise e o entendimento da prática colaborativa na pesquisa. No entanto, faz-se necessário, antes de entrarmos na descrição dos dilemas e nas análises das categorias, explicar, mesmo que de forma sintética, como a colaboração emerge no contexto desta discussão e no âmbito da pesquisa etnográfica crítica de sala de aula, enquanto instrumento de pesquisa que pode contribuir significativamente para um melhor entendimento dos processos interativos de sala de aula.

\section{A colaboração no contexto da pesquisa educacional}

Professores como pesquisadores de sua própria sala de aula e/ou de sua prática pedagógica não são uma novidade entre nós. Professores experientes utilizam esse recurso como uma forma de aperfeiçoamento profissional; os menos experientes usam-no para dividir suas dificuldades pedagógicas com seus pares e receber ajuda para diminuir essas dificuldades. No meio acadêmico, sem tanta freqüência, encontramos trabalhos de tese que descrevem o professor como pesquisador* de sua própria prática (Silva, 1990). Já no início dos anos 80, pesquisas apontam para o professor pesquisador como uma parceria importante a ser 
construída com o pesquisador de sala de aula. Erickson (1986) e Bolster (1983) ressaltam que a pesquisa etnográfica, por sua natureza interpretativa, é intrinsicamente democrática e constitui um deliberado envolvimento do pesquisador com o local da pesquisa, o qual observa com especial atenção as questões que o professor formula na rotina da sala de aula; ressaltam, ainda, que professores experientes servem de modelos para os menos experientes, que o entendimento dos papéis sociais do professor em sala de aula e o significado que estes papéis têm para o contexto maior da escola constituem uma fonte inesgotável de informações para o entendimento dos processos interativos em sala de aula; e que estes professores, por excelência, poderiam descrever o significado da ação local de sua tarefa pedagógica. Os autores entendem que pesquisas conduzidas pelos métodos interpretativos não exigem treinamento especial nem tampouco habilidades específicas para serem conduzidas. $O$ trabalho de campo nessas pesquisas requer habilidades de observação, comparação, contraste e reflexão, que todos os seres humanos possuem; o profissional de pesquisa usa estas habilidades apenas de maneira especialmente sistematizada e de modo deliberado. Portanto, o professor pode, e muito bem, pesquisar sua própria prática. A importância da parceria entre professor e pesquisador bem como a presença do pesquisador evidenciamse porque a prática cotidiana torna-se invisível para aquele que está imerso nela; neste caso, uma pessoa "de fora" pode ajudar a ver mais claramente as complexidades que envolvem as ações cotidianas. No entanto, esta parceria nem sempre é fácil de ser estabelecida.

Somente nos anos 90, pesquisadores de sala de aula começaram a atribuir maior valor à participação dos professores na pesquisa. Daí essas relações serem ainda frágeis e sensíveis, no tocante à sua legitimidade e validade na pesquisa educacional. Pesquisas recentes sobre o cotidiano escolar começam a envolver professores, a falar sobre eles, mas não com eles.

A abordagem etnográfica, por sua natureza descritiva da realidade, rigorosa quanto ao entendimento do significado das ações sociais para o 
outro, quando associada a uma visão crítica da justiça social enquanto abordagem teórica, não pode deixar de reivindicar a parceria do professor para a análise dos processos interativos de sala de aula. Fazer etnografia crítica de sala de aula sem o professor é continuar a falar sobre a realidade dele sem que ele possa sequer opinar sobre o significado de sua prática. Os professores, diferentes de outros profissionais - advogados, engenheiros etc. - , em especial os professores das redes públicas, não têm tido oportunidade de manifestar as dúvidas e os acertos de suas práticas de sala de aula de modo institucionalizado, isto é, suas reflexões contam muito pouco ou não contam, quando das reformulações dos planos pedagógicos institucionais (propostas curriculares e planos educacionais). Menos ainda são considerados por pesquisadores como suporte para reformulações intra-escolares. Estes apontam, quase sempre, o "sistema" como culpado da situação em que se encontra a educação escolar. Os professores, enquanto profissionais de modo geral, têm tido uma postura institucional "infantilizada", como se não fossem profissionalmente capazes de pesquisar suas próprias práticas, ou resolver seus próprios problemas no campo pedagógico. De forma contraditória, politicamente, consideramos os movimentos de classe dos professores como maduros, experientes e combativos, mas em relação às suas práticas pedagógicas os professores consideram-se, na maioria das vezes, despreparados e "necessitados" de "treinamentos" e "reciclagem" pedagógicos. É neste sentido que a postura institucional "infantilizada" atua como um fator, no mínimo, inibidor desta parceria com pesquisadores, fazendo com que os professores se sintam muitas vezes "incapazes" para fazer pesquisa.

Acreditamos, no entanto, que a parceria das universidades com a rede pública de ensino é uma exigência para que as pesquisas educacionais sejam mais relevantes e eficazes na reversão do quadro de falência educacional. Mediante esta parceria, o professor como pesquisador tornase um ator social importante para a facilitação não só das pesquisas nas escolas, mas na determinação do que é importante a ser pesquisado dentro 
da sala de aula e fora dela. Acreditamos, ainda, que em etnografia crítica de sala de aula a colaboração entre professor e pesquisador é condição indispensável para o avanço na pesquisa educacional.

Neste estudo entendemos que a inter-relação entre pesquisa e ensino é parte fundamental do processo de construção do conhecimento em sala de aula e a colaboração, uma prática que possibilita a genuína ajuda mútua e o intercâmbio entre o trabalho de pesquisa e o ensino.

Nesse sentido, a colaboração pode ser condição essencial para o sucesso da prática profissional de professores, alunos e pesquisadores. A atitude colaborativa parece ser uma condição necessária se a prática pedagógica for aprimorada de forma fundamental e duradoura. No entanto, essa mudança pode ser meramente cosmética e passageira, o que é sempre um perigo quando falamos sobre aperfeiçoamento nas escolas.

Colaborar significa trabalhar junto, de modo que possibilite o intercâmbio de ajuda mútua. A troca de ajuda deve ser genuína e não apenas uma ação-ajuda, manifestando-se através dos gestos mutuamente úteis. O professor pesquisador deve estar empenhado na reformulação de sua prática de forma consciente e deliberada, de forma que a pesquisa por ele realizada em conjunto com o pesquisador possa contribuir realmente para uma mudança nas ações pedagógicas, especialmente as de caráter interpessoal. O professor que procura nesta parceria uma nova receita de trabalho está tão equivocado quanto aquele que acredita em reciclagem pedagógica como condição necessária para a reformulação de sua prática. Depositar na pesquisa a solução dos problemas pedagógicos é, no mínimo, romantismo. O que se consegue muitas vezes com esta parceria é a reflexão sistemática e deliberada sobre os pontos que o professor e o pesquisador acreditam representar o nó do processo de ensino-aprendizagem em sala de aula ou fora dela; consegue-se ainda a visualização conjunta de possíveis formas para se desatar esse nó. Esperar mudanças radicalmente miraculosas neste processo é cair novamente na falácia de que existe um modelo certo para um bom desempenho profissional. $\mathrm{O}$ pesquisador, igualmente, deve 
estar consciente de que esse instrumento de pesquisa contribuirá para descrever apenas urna parcela de todo o processo de ensino-aprendizagem, que, por sua complexidade, se dá na sala de aula e tem os seus tentáculos nos vários contextos sociais e ideológicos, nas relações face a face, na família, na mídia, no partido político, na comunidade de bairro, nos rituais religiosos etc. Portanto, é necessário o uso da colaboração como instrumento de pesquisa etnográfica crítica de sala de aula, como também é necessário o estudo mais sistemático dos macrossistemas que determinam as relações de sala de aula: a política escolar, as relações de poder, as estatísticas da fome e da miséria, a análise das relações entre a escola e a sociedade, mediada pela crítica sobre a justiça social, entre outras. Esses estudos podem, igualmente, se realizar através de parcerias, obviamente com outros protagonistas sociais que desfrutam de igual importância para o entendimento da sala de aula e da escola: diretores, legisladores, administradores etc.

\section{O significado da colaboração para os pesquisadores e professores}

Primeiramente, deve-se notar que a colaboração significa para o pesquisador um salto qualitativo na busca do entendimento do significado da ação do outro, que na forma compartilhada ganhou uma nova dimensão: a dimensão da negociação do significado e da participação não invasiva, mas consentida e/ou permitida, que, como tal, está imersa no comprometimento, na responsabilidade com a transformação da realidade cotidiana da sala de aula. Segundo, é igualmente necessário falar do que ela não significa: a colaboração não foi um processo de alcance de pleno acordo entre participantes, nem foi o exercício de um acordo sobre metas e ações preestabelecidas, mediadas pelas práticas curriculares ou pela organização funcional da escola. Ao contrário, foi uma negociação contínua e difícil dos diferentes pontos de vista entre os participantes, 
com o objetivo de compreender esses enfoques e melhorar a educação nas escolas.

Neste estudo apresentaremos dois exemplos nos quais buscamos a colaboração como estratégia de pesquisa. Durante o período de novembro de 1992 a dezembro de 1993, a equipe do "Projeto Fracasso Escolar" trabalhou na coleta de dados, que incluía, entre outros aspectos, estudos sobre a construção do fracasso na sala de aula. Buscamos parceria nas salas de aula ditas "problemáticas", e encontramos duas professoras dispostas a colaborar com a pesquisa. Nossa expectativa era trabalhar com classes de $1^{\mathrm{a}}$ série, mas esta parceria voluntária só foi possível, coincidentemente, nas duas escolas estudadas, com professoras de $4^{\hat{a}}$ série: a da professora Nice, da Escola da Roça, que assim passaremos a chamar por se tratar de uma escola rural do município de Cachoeiras de Macacu, e a da professora Bia, da Escola da Favela, que assim foi denominada por se localizar na zona sul do Rio de Janeiro e por atender uma clientela de $99 \%$ de alunos da favela da Rocinha. As duas professoras participaram do trabalho de forma voluntária e consciente e informaram que nas suas classes o número de alunos fracassados seria de, no mínimo, $25 \%$. Previsão drástica para a maioria da equipe de pesquisa, no entanto, este prognóstico já havia sido denunciado pelo trabalho anterior da coordenadora da equipe de pesquisa (Mattos, 1992). Nesse trabalho, a pesquisadora aponta, como uma das necessidades para se ter uma visão mais clara da expulsão e da reprovação de alunos, o acompanhamento sistemático da sala de aula e a verificação da produção do fracasso dentro da sala de aula. No entanto, a pesquisa desse processo não teria sentido sem a participação das professoras, pois acreditávamos que elas não tinham a deliberada intenção de levar ao fracasso seus alunos, que os mecanismos que as levavam a isso eram a elas imperceptíveis e que, finalmente, nossa pesquisa poderia tornar esses processos mais visíveis para as professores e para a própria equipe. Portanto, era necessário o acompanhamento da produção do fracasso 
desses $25 \%$ da classe e, através das ações pedagógicas, entender a natureza dessa predição tão drástica e ao mesmo tempo tão contraditória. Essa colaboração foi melhor sucedida na Escola da Favela, devido a fatores que não envolveram diretamente as professoras, mas a problemas surgidos com a equipe de pesquisa, que não pôde dar a mesma atenção às duas escolas. Na Escola da Roça, portanto, não foi possível criar laços de confiança entre pesquisadores e professora de modo tão efetivo quanto com a Escola da Favela; por esse motivo, vamos nos deter na descrição dessa última.

\section{Relatos de campo sobre a colaboração entre pesquisadores e professores}

Momentos de avanços e recuos marcaram esse relacionamento colaborativo. Avanços, quando nos aproximávamos (pesquisadores e professora) de uma parceria genuína, realmente colaborativa; recuos, quando, temerosos da perda dessa parceria tão importante para nós, silenciávamos diante das nossas próprias dificuldades em lidar com esse novo tipo de relacionamento. Foram nesses momentos que os dilemas mencionados no início deste estudo ficaram mais evidentes. Um dos dilemas foi o da determinação dos procedimentos de pesquisa. Como poderíamos planejar com antecedência o contexto interativo a ser observado e que respondesse às questões maiores da pesquisa, se havíamos convidado a professora como parceira dessa observação? Como continuar a senti-la como um objeto, se ela era parte integrante da equipe de pesquisa? Como poderíamos confiar na professora como sujeito agente do processo questionador da equipe? A necessidade de uma autoridade compartilhada era colocada em dúvida, pois não queríamos ser interpretados nem como "autoridades no assunto" nem gostaríamos de passar a idéia de que estávamos "tirando o corpo fora", deixando o professor sozinho como pesquisador. Surgia outra necessidade: a de se estabelecer limites para 
preservar a integridade de cada membro da equipe, membros inexperientes que interpretavam a resistência da professora como raiva pessoal ou descontentamento com a equipe. Perguntávamos como posturas conflitantes, entre pesquisadores e professora, poderiam conviver em "colaboração", quando havia necessidade de negociação do significado da ação pedagógica, para que se pudesse prosseguir na busca do entendimento do cotidiano de sala de aula. Estes foram dilemas verdadeiros - conflitos inerentes a posturas igualmente valiosas e a tensões vividas continuamente na prática pedagógica pela professora e pela equipe de pesquisa.

A professora Bia é graduada e cursa, no momento, pósgraduação. Um ponto comum entre ela e a equipe foi o interesse em pesquisa, condição necessária para o desempenho acadêmico da professora e que despertou seu interesse pela pesquisa. No entanto, quando a equipe entrava em sala de aula, mesmo com consentimento prévio, havia a nosso ver uma expressão de desagradável surpresa por parte da professora; a negociação de nossa presença em sala de aula foi sempre um fator de estresse entre nós. A equipe preferia chegar cedo e permanecer o tempo todo, enquanto a professora preferia ter "um descanso" de nossa presença pelo menos durante uma parte do tempo de aula. Sempre que possível, a professora adiava nossas visitas ou perguntava "Será que eu ainda faço parte desta pesquisa?", quando inadvertidamente nos encontrava nos corredores da escola. Dentro desse clima de constante negociação do acesso e permanência da equipe no local, aprendemos que é difícil não sermos considerados "espiões perigosos" da prática pedagógica, como se inerente ao papel de pesquisador estivesse o papel de delator dos erros do professor. A professora sempre expressava uma atitude defensiva em relação às atividades programadas para os "dias de pesquisa", como que se prevenindo de possíveis críticas. Ela dizia: "Eu estou dando isso hoje porque estamos um pouco atrasados com a matéria; não dá pra adiantar e eles ficarem perdidos, né!" Não raro explicava: "Estes eu tenho que deixar 
de lado, pois, você sabe, eles não querem nada, e eu tenho que investir naqueles que têm alguma coisa para trabalhar" (referindo-se ao grupo de 10 alunos entre os 42 da classe, que desde o último conselho de classe de 1992 haviam sido diagnosticados como "os problemas da classe" e haviam sido tomados como "um desafio" pela professora Bia, para o ano letivo de 1994).

Foi em relação a esse grupo de alunos que, contraditoriamente, nossos conflitos (da equipe com a professora) mais se evidenciaram. Em abril, a professora já demonstrava sinais de enfraquecimento na determinação de "converter" os alunos a um status "regular" na classe. No primeiro conselho de classe, por exemplo, ela, por várias vezes, solicitou às outras professoras depoimentos que demonstrassem o quanto era difícil conseguir algum progresso com aqueles alunos, falando: "Você viu, né Regina? (professora da $3^{\mathrm{a}}$ série). Vocês são testemunhas de que eu faço o que posso, mas não sou a palmatória do mundo, têm casos que eu não posso ajudar". Em nenhum momento a professora, considerada pela escola (diretores, orientadores, professores e alunos) como professora experiente, batalhadora, "boa professora", discutiu com a equipe sobre sua estratégia de aula, não questionou se o que estava sendo realizado em sala de aula era importante para os alunos; se o fato de ela ter um grupo seleto de "dez alunos-problema" era um consenso da classe. Diferente da equipe que pensa dialeticamente o ato de ensinar e aprender, ela entendia a tarefa de ensinar dicotomizada com a tarefa de aprender, e considerava que a equipe de pesquisa estava ali para ensinar o que deveria ser feito ou para aprender com o que ela fazia, descrever o sucesso dela em lidar com "os problemas" de forma enérgica e eficaz para a escola (manter os alunos "com dificuldades" longe da secretaria e ocupados "de alguma forma" na sala de aula). A equipe, meio tímida, ainda, esperava pacientemente que a professora tivesse "alguma dúvida", pois nós tínhamos muitas, e estas foram silenciadas ora por medo de romper a parceria, ora por respeito ao ponto de vista da professora. A professora portava-se como que tentando 
ensinar à equipe de pesquisa o que é ser um "bom professor" para esse "tipo de aluno". O nosso objetivo era que ela formulasse algumas perguntas sobre o que estava acontecendo na sala de aula, alguma coisa que ela não compreendesse bem na sua relação com os alunos, e que explicasse o fracasso daqueles alunos, especialmente "os dez mais problemáticos". Mas a professora parecia não ter dúvidas, ao contrário, falava com convicção que as causas para o fracasso tinham a ver com o passado deles em outras turmas, outras professoras, escolas "diferentes", com a origem pobre de suas famílias faveladas, com o desinteresse "vagabundo" deles e dos pais pelas questões da educação e, especialmente, com a falta de uma "educação doméstica" voltada para a escola. Tinha muita certeza sobre sua eficiência, às vezes reconhecida e estimulada pela direção da escola, que, embora não concordasse plenamente com seus métodos, reconhecia ser "um alívio" ter uma professora "disposta a enfrentar" uma classe com tantos "casos problemáticos". A classe era de alunos repetentes. Somente sete dos 42 alunos não eram repetentes; a média de idade era de 14 anos, variando entre 12 e 17; regularmente, esta classe deveria ser povoada por alunos na faixa etária de 10 a 11 anos.

No segundo conselho de classe, um tema comum entre as outras classes da escola não foi mencionado pela professora Bia: vários professores reclamaram dos alunos e de suas brincadeiras em sala, destacando um especial interesse por brincadeiras de natureza sexual, consideradas "fora de horário e de propósito". Não vamos descrever aqui a natureza das brincadeiras e o conteúdo das reclamações dos professores por não serem relevantes para este estudo. $\mathrm{O}$ importante neste momento é o registro da discrepância entre a turma de Bia e as outras quanto à abordagem do assunto "sexualidade", visto que, sendo uma turma de idade mais avançada, obviamente poderia ter mais problemas que as outras com essas brincadeiras. A turma de Bia foi considerada um exemplo para as outras, em saber como lidar com "esses assuntos", afirmação feita por uma das orientadoras durante a reunião. Este fato fez com que a equipe 
sentisse a necessidade de estudar mais de perto os alunos da classe de Bia, acentuando mais ainda nossas relações conflitantes. Queríamos saber melhor como eles eram, o que faziam, como viviam, que conhecimentos tinham sobre a vida do adulto - família, trabalho, diversão, sexo, droga, entre outros, eram os temas que queríamos ouvir dos alunos. Bia ficou muito assustada com a proposta, chegando mesmo a impedir nosso acesso aos alunos para uma entrevista particular, por algum tempo. Pensamos primeiro num questionário, que foi vetado por Bia, por considerar os alunos "imaturos" para as questões nele propostas (especificamente aquelas que perguntavam sobre o conhecimento dos alunos em relação ao sexo e ao uso de drogas). Eliminamos o questionário e pensamos numa redação, que foi consentida pela professora e solicitada aos alunos. Após o estudo das redações, cujo tema versava sobre a "A vida de um menino na cidade do Rio de Janeiro", realizamos algumas entrevistas, nas quais a "colaboração" por parte da professora foi, no mínimo, questionável. Ela preveniu os alunos sobre as possíveis questões baseadas nos questionários e sugeriu algumas respostas, além de tentar controlar a formação dos pares de alunos que deveriam ir juntos para as entrevistas, evitando, assim, combinações consideradas por ela "desastrosas". Ela falava: "Estes dois juntos... Deus me livre! É melhor separar, senão só sai asneira". As entrevistas foram realizadas com perguntas abertas, bem diferentes das perguntas dos questionários, e os próprios alunos falaram espontaneamente sobre suas vidas. A tranqüilidade com que as entrevistas ocorreram foi acalmando a professora que, ao final, já não se importava mais com o fato. Aprendemos com as entrevistas que, ao contrário do que havia ocorrido no conselho de classe, a turma de Bia também brincava das mesmas coisas que as outras, só que, por temer punições, conseguiam esconder o fato sem deixar vestígios. Descobrimos, ainda, que, como era de se prever, os alunos de Bia tinham experiência sobre sexo e droga, o que não coincidia com o perfil descrito pela professora. Bia evitava "esses assuntos", temendo excitar a curiosidade dos alunos sobre os mesmos. 
O fato é que aprendemos muito com Bia. Ela é desconfiada em relação ao uso que se possa fazer das informações obtidas em sua classe, pois, de maneira geral, o professor é visto como "o vilão que leva o aluno ao fracasso", seja por "incompetência técnica", seja por "descompromisso político". Dentro de seus limites, no entanto, ela corajosamente "permitiu" que nossa equipe compartilhasse vários momentos difíceis em sala de aula, demonstrando que dentro desta parcela a tarefa de promover o fracasso de alunos não era bem compreendida por ela. Bia sabe que dentro de seus próprios limites ela é uma "professora" com todas as letras e desconhece "o porquê" do fracasso de seus alunos. Aprendemos que tínhamos que ter a coragem que Bia teve e arriscar mais nesta parceria, já que fomos nós que a propusemos; que deveríamos ter confiado em nossa capacidade de negociar, perdemos, assim, oportunidades mútuas de estudo e discussão. Foi somente no final do trabalho de campo que isso se tornou mais visível. Durante o último conselho de classe, Bia, como estava previsto desde o início do ano, "teve" que reprovar os "dez alunos-problema" e passou "maus bocados" perante o grupo de professores, orientadores e diretores para se manter coerente diante das decisões que tomara. Foi solicitado que ela considerasse algumas aprovações desses alunos; ela, "consciente" do papel que desempenhara o ano inteiro (o de tomar conta e dar conta dos "alunos-problema"), disse ao grupo: "bem, eu fiz o que pude, mas aprovar é fora do meu alcance. Vocês me entendem, eles não sabem nada, como é que vão para a $5^{\text {a }}$ série assim? Depois, 'bate' na mão de alguém que não me conhece e que vai pensar que eu não dei aula". Diante do solitário papel de "carrasco" que lhe fora atribuído, não nos restou outra alternativa que a de interferir em favor da professora, ressaltando a coerência entre o ato de reprovar os dez alunos e a prática que havia desenvolvido durante o ano letivo, quando os demais colegas só lhe exigiram uma postura rígida de controle da turma, sem levar em conta outros fatores que eram reivindicados pela direção como pontos fundamentais para a tomada de decisão sobre o destino daqueles alunos. 
A professora, após ouvir nossa intervenção, falou: "agora, sim, valeu, ganhei o meu dia, valeu a pena...", como que reconhecendo, naquele momento, que ela tinha construído uma parceria genuína, finalmente, que nós não estávamos do lado dos alunos e, sim, do lado dela. Embora tenha sido este o pensamento da professora, não foi o da equipe que o tempo todo procurou estar de ambos os lados (da professora e dos alunos). Mas foi gratificante, mesmo assim, saber que, naquele momento, a professora encontrou em nós um aliado para uma decisão que, para nós, estava equivocada desde o início do ano, mas que com certeza, estava coerente em relação a tudo o mais que acontecera na sala de aula durante aquele ano letivo.

Inúmeras passagens poderiam ser relatadas, nas quais os limites do processo de colaboração convergiram e divergiram durante esse ano de trabalho de campo, mas vamos nos limitar agora a descrever as categorias ou temas com os quais nos defrontamos durante esse processo de busca da colaboração e que nos propusemos analisar no início deste ensaio: o diálogo, a confiança e o risco.

O diálogo

Aprendemos com esta experiência que na pesquisa colaborativa o diálogo face a face é um componente indispensável para a construção de uma colaboração genuinamente de mútuo interesse. A conversa clara e aberta sobre intenções, expectativas, opiniões e preocupações que envolvem o trabalho de pesquisa e a tarefa pedagógica do professor devem ser amplamente debatidas e compartilhadas ora de forma sistemática e planejada, ora de maneira informal e espontânea em reuniões, jornais compartilhados (onde professores e pesquisadores escrevam suas dúvidas e possam conversar por escrito) e conversas sistemáticas.

Nossa experiência anterior em pesquisa etnográfica evidencia que o pesquisador fica inibido nesta ampla participação e diálogo aberto, 
tentando manter a postura de "nao interferir no contexto", perdendo, assim, a oportunidade de se aprofundar no entendimento do significado da ação do outro e cometendo erros de interpretação que podem perdurar durante muito tempo até que sejam detectados. Com este envolvimento aberto ao diálogo, o pesquisador pode evitar julgamentos precipitados, recebendo ajuda do professor e interpretando de forma mais coerente a natureza das suas ações cotidianas.

Pesquisadores e professores abertos ao diálogo promovem uma relação mais simétrica em termos de poder - relação pesquisador/ pesquisado. Uma relação assimétrica de poder é quase sempre inerente ao processo de pesquisar e isto impede uma colaboração completa. $\mathrm{Na}$ entrevista etnográfica, por exemplo, o etnógrafo repete a fala do professor, parafraseando o entrevistado, de modo a evitar a inclusão de conteúdos agendados pelo pesquisador, mantendo-se distante do contexto do professor, de modo a não interferir na resposta deste. Em colaboração, no entanto, a agenda deve ser de ambos, que em diálogo, sistemático (entrevista) ou não, conversam e contam estórias que ambos partilharam no trabalho de campo. Neste caso, uma outra limitação presente na postura do etnógrafo tradicional, a de não expressar sua própria opinião ou de não falar sobre sua própria experiência, fica liberada, promovendo um diálogo onde o compartilhamento de idéias tem igual peso para colaboradores em igualdade de condições.

\section{A confiança e o risco}

Estas duas categorias de análise, no contexto do estudo sobre a colaboração, aparecem juntas por serem interdependentes. Não há colaboração sem confiança, e esta confiança, de uma forma ou outra, envolve riscos. Na colaboração entre professores e pesquisadores, a confiança de que o pesquisador sabe alguma coisa que o professor não sabe (geralmente o pesquisador tem maior grau de escolarização e não 
raro carrega o mito de ser "o cientista" e, portanto, aquele que "faz ciência") sinaliza ao professor a possibilidade de ajuda, conselhos e soluções para seus problemas. Porém, aconselhar professores sem ter sido solicitado não é colaboração. Se os pesquisadores apenas mantivessem suas bocas fechadas e concordassem completamente com a agenda estabelecida pelos professores, esta atitude não seria colaborativa porque envolveria falsidade, seria um silenciar não autêntico de opiniões da equipe. Ambos, professores e pesquisadores, possuem as peças do quebra-cabeça, mas as peças são diferentes, portanto, temos que confiar no conhecimento mútuo sobre determinado tema, também de interesse mútuo. $\mathrm{O}$ pesquisador, por sua vez, tem de confiar que o professor será fiel à parceria, que estará aberto às perguntas da pesquisa; tem de acreditar que o professor sabe sobre sua prática, embora muitas vezes não tenha as informações arrumadas da forma que o pesquisador as tem; tem de confiar que o professor pode descrever e solucionar problemas aos quais os pesquisadores não estavam atentos. $\mathrm{O}$ risco na confiança conduz a momentos de recuo e de avanços, nos quais algumas vezes se tem certeza e noutras, dúvidas, sobre uma mesma ação ou procedimento. Como explicar que um professor consciente de sua tarefa de educador possa reprovar um aluno com base no mau comportamento deste aluno? Como confiar na certeza do professor sobre sua prática, quando este acredita ter um "aluno problema" e ao mesmo tempo usa de ironia durante quase todas as aulas de um ano letivo, demonstrando descaso pelo "problema desse aluno"? Discernimento sobre os problemas da escola, em geral, pode nos ajudar a conviver melhor com esses dilemas, mas não devemos esperar que mesmo um profundo discernimento vá promover um "arranjo" para a solução dos dilemas da ação colaborativa na pesquisa. É preciso, definitivamente, conviver com os dilemas e confiar no professor e na equipe de pesquisa, que, através de uma acomodação mútua, compartilham suas certezas e incertezas, construindo a colaboração de forma genuína e duradoura.

R. bras. Est. pedag., Brasília, v.76, n.182/183, p.98-116, jan./ago. 1995 


\section{Concluindo}

Analisando as condições de desenvolvimento da pesquisa etnográfica crítica de sala de aula e suas limitações no âmbito da escola pública, concluímos que essa abordagem é um instrumento valioso nas investigações do processo de ensino-aprendizagem, quando associada a uma efetiva e genuína colaboração entre professores e pesquisadores. Acreditamos que esse procedimento merece maior atenção por parte daqueles que se preocupam em investigar o contexto da sala de aula e as inter-relações que nele se evidenciam, em especial, as relações face a face.

\section{Referências bibliográficas}

BOLSTER, A. S. Toward a more effective model of research on teaching. Harvard Educational Review, v.53, n.3, p.94-308, 1983.

CAMPBELL, D. Collaboration and contradiction in Staff Development Project. Teachers College Record, n.90, 1988.

ERICKSON, F. Qualitative research on teaching. In: WITTOROCK, M. (Ed.). Handbook of research on teaching.?), ed. New York: Macmillan, 1986.

LAMPERT, M. How do teachers manage to teach? Perspectives on problems in practice. Harvard Educational Review, v.55, p. 178-194, 1985.

MATTOS, Carmen Lúcia Guimarães de. Piciuring school failure: a study of diversity in explanations of "educational difficulties" among rural and urban youth in Brazil. Tese (Doutorado em Educação) Graduate School of Education, University of Pennsylvania, USA.

SILVA, Terezinha M. Nelli. A construção do currículo na sala de aula: o professor como pesquisador. São Paulo: EPU, 1990. 
Recebido em 18 de novembro de 1994.

Carmem Lúcia Guimarães de Mattos, Ph.D. em Educação pela University of Pennsylvania, USA, é professora do Departamento de Teoria e Prática de Ensino da Faculdade de Educação da Universidade Federal Fluminense (UFF).

This essay concerned with a research experience involving teachers and researchers as collaborators. Uses data from the ethnographic study entitled: "School failure: Images of popular explanation about 'educational difficulties ' among you th from rural and urban areas of the State of Rio de Janeiro". Il describes how the collaborative practice is important to facilitate the transformation of classroom interaction when one considers teachers as collaborators and human agent of the research. It visualizes the interrelation between research and teaching as essential part of the construction of knowledge in the classroom and the collaboration as a practice that makes possible a genuine mutual help and an interchange between researching and teaching work. It analyses the condition and limitation for developing this type of research within public schools. It understands that critical ethnography of the classroom as well as collaboration between teachers and researches constitute elements for the advancement of the educational research field in Brazil that needs special attention from researchers in this area of study.

Il s'agit dans cet essai du rapport sur des experiences de la collaboration entre les professeurs collaborateurs et chercheurs. On s'y sert de données de la recherche ethnographique dont le titre est: Echec Scolaire: Images d'explications populaires sur 'les difficultés educationnelles ' entre les jeunes de régions rurale et urbaine à l 'État de Rio de Janeiro. On y décrit que la pratique en collaboration est essentielle à la facilitation et à la transformation des rapports d'interaction dans la salle de classe, quand on considère que le professeur collaborateur est un agent de la recherche. On y voit l 'interaction entre l'enseignement et 
la recherche comme partie fondamentale du processus de construction de connaissances dans la salle de classe et la collaboration comme une pratique qui permet la véritable coopération et l'échange entre la recherche et l'enseignement. On y analise la recherche dans les écoles publiques. On y comprend que l'ethnographie critique de la salle de classe aussi que la collaboration entre professeur et chercheur dans la recherche éducationnelle constituent des éléments de croissance de la recherche éducationnelle au Brésil qui mérite un regard spécial parmi les chercheurs de ce domaine.

Este ensayo trata del relato de experiencias sobre colaboración en pesquisa entre profesores colaboradores y pesquisadores. Utiliza datos de Ia pesquisa etnográfica titulada: "Fracaso escolar: Imágenes de explicaciones populares sobre 'dificultades educacionales ' entre jóvenes de áreas rural y urbana en el Estado de Rio de Janeiro ". Describe que la práctica colaborativa es esencial para la facilitación y transformación de las relaciones de interacción en sala de clase, cuando consideramos que el profesor colaborador es un agente de la pesquisa. Ve a la interrelación entre pesquisa y enseñanza como parte fundamental del proceso de construcción del conocimiento en sala de clase y a la colaboración como una práctica que posibilita la genuina ayuda mutua e intercambio entre el trabajo de pesquisa y la enseñanza. Analiza las condiciones de desarrollo deste tipo de pesquisa e escuelas públicas y sus limitaciones. Entiende que tanto la etnografia crítica de la sala de clase como la colaboración entre profesor y pesquisador, en la pesquisa educacional, constituyen elementos para un avance en la pesquisa educacional en el Brasil, mereciendo especial atención entre pesquisadores en esta área de estudios. 